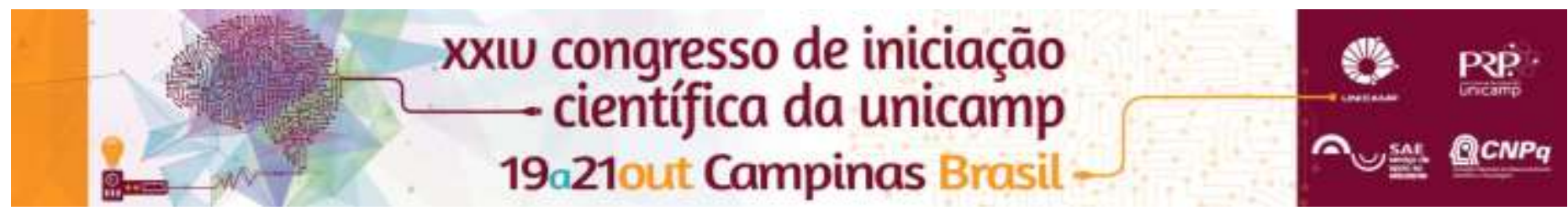

\title{
QUANTIDADE DE FALA, INTENSIDADE DE VOZ E SINTOMAS VOCAIS DE ALUNOS DO CURSO DE ARTES CÊNICAS DA UNICAMP.
}

\author{
Nívia D. C. de Jesus*, Ana Carolina Constantini
}

\begin{abstract}
Resumo
Dentre os campos de atuação do fonoaudiólogo encontra-se o da voz. A atuação nesta área consiste na orientação, prevenção, promoção, avaliação, diagnóstico e tratamento das desordens vocais. As pessoas que utilizam a voz como instrumento de trabalho são chamadas de profissionais da voz, estando o ator de teatro incluído neste grupo de profissionais. Uma das formas de prevenir futuras desordens vocais nestes sujeitos é focar a atuação desde a formação destes profissionais. Assim, os alunos do curso de artes cênicas da UNICAMP constituem o foco deste estudo.
\end{abstract}

\section{Palavras-chave:}

Voz profissional, sintomas vocais, prevenção.

\section{Introdução}

Dentre os campos de atuação do fonoaudiólogo encontra-se o da voz. A voz é responsável por uma grande parcela das informações contidas em uma mensagem e revela, muitas vezes, as características de cada falante. Tais características podem ser, por exemplo, timidez, fragilidade, infantilidade, entre inúmeras outras. Outros autores como Koufman (1991) e Behlau (2001) também abordam a importância de uma qualidade de voz boa ao afirmarem que, para os atores de teatro, o grau de risco de desenvolver um problema vocal é elevado. Portanto, qualquer alteração vocal, mesmo que discreta, pode causar sérias consequências para sua atividade profissional, como diminuir a flexibilidade vocal, que pode ser imprescindível na criação de uma personagem, por exemplo. Assim, vê-se a importância da promoção e prevenção no que tange o uso da voz principalmente durante a formação destes profissionais, já que a probabilidade de várias desordens vocais serem prevenidas é bastante alta.

Objetivos: Identificar e analisar a quantidade de fala e intensidade de voz, juntamente aos possíveis sintomas vocais que os alunos de graduação do curso de artes cênicas podem apresentar no decorrer dos quatro anos de curso.

\section{Resultados e Discussão}

A média de idade dos participantes da pesquisa (alunos do curso de graduação dos $1^{\circ}, 2^{\circ}$ e $4^{\circ}$ anos em Artes cênicas do IA/UNICAMP) é de 20,7 anos de idade. Em relação ao gênero (masculino e feminino), os dados analisados revelam que existe maior prevalência de mulheres no curso de artes cênicas, tanto de modo geral (64\% dos participantes), como na análise por turma. Sendo assim, a maior prevalência de mulheres no curso de artes cênicas, associado ao uso vocal intenso (e nem sempre saudável) que o desenvolver da profissão exige poderia ser um fator contribuinte para o aparecimento de disfonia nesta população. Para a obtenção dos resultados foi aplicado um questionário até o presente momento, porém o estudo conta com a aplicação de 2 questionários e a análise ocorrerá através da computação final do score de cada questionário e, após execução de análise estatística, os resultados de ambos os questionários poderão ser correlacionados.

\section{Conclusões}

Os dados obtidos sugerem que os participantes do estudo se consideram como pessoas que falam em maior quantidade e em maior intensidade que a média. Assim sendo, estes sujeitos utilizam a voz de maneira bem parecida nas situações consideradas habituais e nas situações consideradas acadêmicas, mostrando que há um uso intenso da voz e em grande quantidade para além do que é esperado nas atividades relacionadas ao teatro, que poderia ser explicado por fatores como personalidade mais expansiva, por exemplo, sugerindo que a população que opta por um curso de Artes Cênicas já é propensa a falar em quantidade e intensidade maior que a média. Estes resultados evidenciam uma população de grande importância para a realização de atividades de prevenção e promoção de saúde vocal. A coleta de dados de alunos do terceiro ano, bem como a aplicação do Questionário 2 e a realização de testes estatísticos que possam correlacionar os dados obtidos trará maiores informações a respeito do perfil do uso vocal desta população

\section{Agradecimentos}

Agradeço a minha caríssima professora e orientadora Ana Carolina Constantini por todo empenho, aos alunos do curso de Artes Cênicas da UNICAMP e a FAPESP pelo fundamental apoio dado para a realização da presente pesquisa.

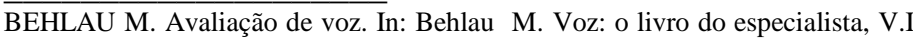
Rio de Janeiro: Revinter, 2001. Avaliação de voz. In: Behlau M. Voz: o livro do especialista, V.II

Rio de Janeiro: Revinter, 2005.

NASCIMENTO M.A, FERREIRA L.P. Voz Ativa: falando sobre o profissional da voz. São Paulo: Roca, 2000.

VALLE M.C. O Conhecimento de atores de teatro amador e profissional sobre o trabalho fonoaudiológico em teatro e a higiene vocal. Faculdades Metropolitanas Unidas. São Paulo, 2008. 